\title{
Endocarditis due to Micrococcus sedentarius incertae sedis
}

\author{
D. C. OLD AND G. P. MCNEILL \\ From the Departments of Bacteriology and Medicine, University of Dundee Medical School, \\ Ninewells Hospital, Dundee DD1 9SY, UK
}

SUMMARY The clinical and bacteriological features of a case of endocarditis are described in which a Gram-positive coccus, presently designated Micrococcus sedentarius incertae sedis, was repeatedly isolated.

When micrococci are isolated in large numbers from the urines of patients with urinary tract infections or from the blood of patients with septicaemia or endocarditis, it should be borne in mind that the micrococci may be the primary pathogens and should be fully identified (Stokes, 1975).

This paper records such a case which appears to be the first of bacteriologically confirmed endocarditis due to Micrococcus sedentarius.

\section{Case report}

A girl with Fallot's tetralogy had right and left Blalock operations performed in childhood. After initial symptomatic improvement, her condition deteriorated and she became breathless and tired after only slight exertion. At operation in December 1976, when she was aged 14 years, a ventricular septal defect, pulmonary stenosis, primitive left ventricle, large secundum atrial septal defect, and hypoplastic mitral valve were detected. Dacron patches were used to create a ventricular septum and to close the atrial septal defect. The pulmonary stenosis was repaired and the right Blalock shunt was closed; the left Blalock shunt could not be reached.

After this difficult operation she remained pyrexial and developed pleural effusions. Neither blood nor effusions yielded growth on culture, but Pseudomonas aeruginosa was isolated from the sputum, and short courses of gentamicin and carbenicillin were prescribed. It was felt that her persisting heart failure was due to a small residual ventricular septal defect and hypoplastic mitral valve. Over the ensuing months she had an intermittent pyrexia and lost $16 \mathrm{~kg}$ in weight. Two episodes of haemoptysis and pleuritic pain suggested that right-sided endocarditis was present. Because her lack of improvement might

Received for publication 22 February 1979 also have been due to tuberculosis, a short course of antituberculosis drugs was given although the Mantoux test was negative.

In July 1977 , two weeks after dental fillings without prophylactic antibiotic cover, she was admitted with symptoms of diarrhoea and vomiting to an infectious diseases hospital. Splenomegaly and splinter haemorrhages were present. At that time the haemoglobin was $7 \cdot 4 \mathrm{~g} / \mathrm{dl}$ and blood urea $30 \mu \mathrm{mol} / \mathrm{l}$. Haematuria and proteinuria were detected and a renal biopsy showed focal proliferative glomerulonephritis. A diagnosis of infective endocarditis causing anaemia and nephritis was made.

All of seven blood specimens, drawn aseptically during the first two days after her admission and cultured by conventional techniques in bottles containing cooked meat broth, yielded growth of a micrococcus. Before our reports of this isolation, therapy with benzylpenicillin and erythromycin had been initiated and was continued for three weeks, during which time further blood cultures were sterile. On transfer to another hospital the patient was treated orally with rifampicin and fucidin. Her condition did not improve markedly, and 65 days after admission the patient relapsed; micrococci were then cultured from another four sets of blood. It transpired that the patient had been hiding her tablets. After compliance was obtained, the patient made uninterrupted progress during treatment for six weeks with ampicillin and vancomycin. Now, two years after the final operation, she is free of cardiac failure and is breathless only after severe exertion. She has gained $16 \mathrm{~kg}$ in weight and there is no splenomegaly. Her haemoglobin is $12.9 \mathrm{~g} / \mathrm{dl}$ and the blood urea level has fallen to $8.4 \mu \mathrm{mol} / 1$.

BACTERIOLOGICAL FINDINGS

From all bottles that yielded growth we isolated a 
Gram-positive coccus, occurring mainly in packets but with some tetrads. It grew poorly on blood agar in air, and well in an atmosphere with $8 \% \mathrm{CO}_{2}$. The colonies were convex, pale-cream, smooth, dull, and, on prolonged incubation, wrinkled and brown. Growth in broth was granular with much sediment. The organism was catalase positive and coagulase and deoxyribonuclease negative and appeared to be a micrococcus. Its additional biochemical properties were: phosphatase negative, oxidase negative, no growth in Simmon's citrate medium, growth on salt agar with up to $10 \%(\mathrm{w} / \mathrm{v}) \mathrm{NaCl}$, acetylmethylcarbinol negative, nitrates not reduced and acid not produced from arabinose, fructose, lactose, maltose, mannitol, ribose, sucrose, trehalose, xylitol, and xylose (Cross-Infection Reference Laboratory, Colindale, and Dr A. C. Baird-Parker; personal communications). These properties are closest to those of $M$. sedentarius (Kloos et al., 1974).

Sensitivity to antibiotics was determined by the disk diffusion technique performed on sensitivity agar (Oxoid), inoculated with a suspension of micrococci adjusted to give near-confluent growth and incubated in the presence of $\mathrm{CO}_{2}$. The micrococcus was sensitive to ampicillin $(25 \mu \mathrm{g})$, chloramphenicol $(10 \mu \mathrm{g})$, erythromycin $(10 \mu \mathrm{g})$, gentamicin $(10 \mu \mathrm{g})$, kanamycin $(5 \mu \mathrm{g})$, neomycin $(10 \mu \mathrm{g})$, streptomycin $(10 \mu \mathrm{g})$, rifampicin $(5 \mu \mathrm{g})$, tetracycline $(10 \mu \mathrm{g})$, and vancomycin $(30 \mu \mathrm{g})$; it was resistant to cloxacillin $(5 \mu \mathrm{g})$ and clindamycin $(2 \mu \mathrm{g})$. There was no inhibition of growth of the micrococcus in the presence of $6 \mathrm{mg} / \mathrm{l}$ benzylpenicillin or $10 \mathrm{mg} / \mathrm{l}$ methicillin. The property of resistance to both benzylpenicillin and methicillin is considered specific for M. sedentarius (Kloos et al., 1974).

\section{Discussion}

Before the era of modern cardiovascular surgery, endocarditis was most commonly associated with viridans streptococci, but other organisms including micrococci are now reported as infrequent causes of endocarditis. Thus, Keys and Hewitt (1973), in a 16-year survey, recovered micrococci of unknown species from eight patients after heart surgery and from another seven patients after urological manipulation, dental treatment, or cardiac catheterisation. Six of the seven medical cases were cured but only four in the surgical group.

The status of the organism $M$. sedentarius incertae sedis (Baird-Parker, 1974), first isolated from sea water and described by ZoBell and Upham (1944), is currently under review by the ICSB Subcommittee on the Taxonomy of Staphylococci and Micrococci. Unlike other micrococci, such as $M$. mucilaginosus incertae sedis (Rubin et al., 1978), reported as agents of endocarditis, M. sedentarius i.s. is not a known member of the oral flora and was not recovered from mouth or gum swabs from this patient. How she acquired this organism, therefore, is difficult to explain. That she did so during dental treatment is a possibility, but in view of the observation that she was intermittently pyrexial in the months before admission, her endocarditis might have antedated her dental treatment. A recent study in the USA by Kloos et al. (1974) reported the recovery of $M$. sedentarius i.s. from the healthy skins of $13 \%$ of 115 persons examined. It is possible, therefore, that her infection was endogenous but we have no information about her skin carriage of micrococci.

This diagnosis of endocarditis due to $M$. sedentarius i.s., based on its repeated recovery from many blood cultures, appears to be the first description of infection by this organism. Although its role as an opportunistic pathogen is likely to be limited by ecological factors, we note that a micrococcus with very similar properties, but much more drug resistant, has been isolated from a patient with a prosthetic heart valve (Cross-Infection Reference Laboratory, Colindale; personal communication).

We acknowledge the valuable help of the CrossInfection Reference Laboratory, Colindale, London, Dr A. C. Baird-Parker of Unilever Research, and $\mathrm{Mr}$ B. Foreman in the characterisation of this organism.

\section{References}

Baird-Parker, A. C. (1974). Micrococcus. In Bergey's Manual of Determinative Bacteriology, 8th edition, edited by R. E. Buchanan and N. E. Gibbons, pp. 478483. Williams and Wilkins, Baltimore.

Keys, T. F., and Hewitt, W. L. (1973). Endocarditis due to micrococci and Staphylococcus epidermidis. Archives of Internal Medicine, 132, 216-220.

Kloos, W. E., Tornabene, T. G., and Schleifer, K. H. (1974). Isolation and characterisation of micrococci from human skin, including two new species: Micrococcus lylae and Micrococcus kristinae. International Journal of Systematic Bacteriology, 24, 79-101.

Rubin, S. J., Lyons, R. W., and Murcia, A. J. (1978). Endocarditis associated with cardiac catheterization due to a gram-positive coccus designated Micrococcus mucilaginosus incertae sedis. Journal of Clinical Microbiology, 7, 546-549.

Stokes, E. J. (1975). Clinical Bacteriology, 4th edition, p. 117. Arnold, London.

ZoBell, C. E., and Upham, H. C. (1944). A list of marine bacteria including descriptions of sixty new species. Bulletin of the Scripps Institution of Oceanography of the University of Califorria, 5, 239-292.

Requests for reprints to: Dr David Old, Bacteriology Department, Ninewells Hospital, Dundee DD1 9SY, UK. 